\title{
Strengths and Dysfunctionalities of Formative Assessment: A Short Analysis from the Perspective of Romanian Education
}

\author{
Valerica Anghelache ${ }^{*}$
}

\section{Teacher Training Department, “Dunărea de Jos” University of Galati, Romania}

\begin{abstract}
Evaluation reflects the educationalists' interest in understanding and improving the techniques and instruments of school assessment. Postmodern didactics brings forth a fresh perspective on the evaluation act, which is analysed not only as the final act of the instruction process, but also as a process meant to permanently adjust teaching and learning acts. The aim of this paper is to underline the evolution of evaluation theory and practice in Romanian education, emphasising both its benefits and drawbacks. The paper uses the extant research in the literature as well as personal knowledge of the author about the factors that are related to the improvement of didactic evaluation. Most of the results of these studies lead to the conclusion that building a culture of evaluation is necessary, that formative evaluation should valorise a wide range of strategies and docimologic tools in order to attain an objective evaluation, and to be able to employ its outcomes in designing the teaching-learning undertaking
\end{abstract}

Keywords: Evaluation, performance, objectivity, evaluative strategies, evaluative skills.

\section{INTRODUCTION}

The problem of evaluation is widely tackled in the specialized literature, which proves its great importance. Having this aspect in mind, one may be tempted to think that everything that matters in point of didactic evaluation has already been said. The conceptual apparatus has been improved, the evaluation forms and methods have been analysed, the docimologic instruments have also been improved, and the effects of evaluation have been assessed. Nevertheless, experience has proven that the evaluation process is dynamic, perfectible, and prone to epistemological amendments and rearrangements.

As a rule, evaluation accompanies all our actions. The decisions we make in our daily lives are the outcome of some assessments, of some previous evaluations of the situations, people or contexts. Everything practically subjects to the efforts of measuring, quantifying, validating or examining.

My contention is that, in the field of education, assessment may be analysed from two different perspectives, both subsuming distinct action levels:

a) The systemic, macro-educational perspective, which targets:

\section{- $\quad$ The political level}

Here, the educational policy of evaluation is defined, while also establishing the aims of the evaluation

*Address correspondence to this author at the Teacher Training Department, "Dunărea de Jos" University of Galati, Romania;

E-mail: vali_ang@yahoo.fr undertaking and the priorities. Relevant for this level are the decision-makers who elaborate laws and methodologies in the field of educational assessment.

b) The didactic, micro-educational perspective, which analyses evaluation at the level of the actual teaching process:

- The administrative and scientific level

It may be considered an intermediate level, where evaluation professionals play an important role. The administrative aspect reflects in the assessing procedures and in the management of the evaluation outcomes at the level of each school. At the scientific level, an important role is that of the evaluation professionals, who elaborate or permanently improve the standardised docimologic instruments.

\section{- $\quad$ The pedagogical level}

It refers to the actual evaluation, as it is carried out in each class. This level involves the teachers, who decide the actual objectives of evaluation, contents, evaluation strategies and instruments, and also the ways of amending or improving students' school performance.

From an educational point of view, evaluation targets not only students, but also teachers and education institutions (the school). The outcomes of the students and school after evaluation represent extremely relevant information. Thus, education institutions have the chance of improving their management activities, of adapting their educational offer to the teachers' and students' needs, and of anticipating their evolution in the community. 
For teachers, evaluation represents a way of validating their training, an acknowledgement of their merit and professional qualities, and also a way of becoming aware of the efficiency of the teaching undertaking. In the case of students, evaluation orders the learning process, being a barometer of the intellectual activity employed in acquiring knowledge or skills. Didactic assessment is also important for parents, who have the possibility to know the success level of their child, thus adjusting their expectations at the performance level validated by evaluation.

One could say that the results of the evaluation process of schools, teachers and students are also important for the community or for the entire society. These results illustrate the efficiency of education, providing predictable points of reference for the image of a future society. Moreover, these results are also relevant for the quality and amount of investment in education.

Regardless of its form - initial, formative or summative - didactic assessment may also be analysed from a psychological perspective. From the cognitive point of view, evaluation underlines the manner in which the teacher and the students understand the assessment process, the way in which they are aware of the importance and of the effects of this undertaking. Each of them accesses their own way of thinking, their own standards, perceptions and representations of the didactic assessment. From the affective point of view, the assessment act triggers various affective states, which are enhanced by previous experiences, motivations or expectations. Also, evaluation generates effects at the level of the student's behaviour and attitude. The evaluation pursued by the teacher entails some symbols, which may alter or improve the student's activity towards teacher and learning.

Laying particular focus on the pedagogical level of assessment, this paper aims at analysing the strengths and the potential dysfunctionalities of formative assessment, from the perspective of Romanian education.

But what is formative assessment? Our definition is in compliance with the definitions provided by specialists in Education Sciences. Formative assessment is a form of didactic assessment which takes place along the entire learning activity during a semester or school year. The students are permanently assessed during every lesson, or in reference to every learning unit, this assessment having both amending and motivational role.

In order to attain the formative goal of the assessment, the teacher should permanently answer to a few fundamental questions: Why do we assess? What are we assessing? What the criteria for students' assessment? How do we assess? What are the effects of assessment?

\section{LITERATURE REVIEW}

Teaching experience and the writings of the docimology experts meet in a fundamental aspect: the assessment process can only be analysed in an interdependence relation to the teaching and learning processes. The explanation is very simple: the results of assessment reflect the quality of teaching and learning. Also, a foray into the depth of the relation between the three processes may underline, at any point, the importance of some variables which the teacher should consider, and which are closely related to the previously announced questions.

Thus, Black and Wiliam (2009, p. 6) consider that the teacher should focus on the intervention aspects of the assessment in order to adjust the students' learning activity. Moreover, the teacher's intention with regard to learning must be known by students from the beginning in order to predetermine the aims of the learning activity. Equally important is the quality of feedback and the discourse type promoted by the teacher. In our view, feedback is fundamental in the case of formative assessment, but its promptitude and consistency are also relevant. The school grade represents a feedback, indeed, but without additional explanations, meant to help the students understand what they did right and where they should improve, the assessment does not acquire a formative character.

In what the assessment manner is concerned, Wiliam and Thompson (2007, as cited in Black \& Wiliam, 2009, p. 8) consider that formative assessment is based on five key-strategies:

- Clarification of the criteria of successful learning;

- $\quad$ Class conversations and learning tasks which facilitate the understanding of the information received;

- $\quad$ Feedback;

- $\quad$ Activation of students as learning resource for the others, and 
- Students' empowerment towards their own learning process.

The efficiency of formative assessment also depends on the testing skills of the teacher. Along these lines, Nyberg and Olander (2015, pp. 53-74) underline the necessity of developing the teachers' skills in order to pursue an efficient formative assessment. In a study conducted in two primary schools from Sweden, they explored the formative assessment strategies employed by teachers, based on the variation theory. Their outcomes allow three distinct directions for action:

- $\quad$ awareness of the critical aspects of a learning content;

- $\quad$ teacher's awareness of the students' possibility to learn the respective content;

- $\quad$ exploration/promotion of formative feedback in the relationships with the students.

My contention in this respect is that assessment is not a priori formative, but acquires formative qualities. Bennet (2011) maintains that formative assessment is able to improve the students' performance based on the assessment instruments used and on the docimologic skills of the teacher. It is also important for the teachers to refer to learning theories, to understand how the students learn, in order to provide them appropriate feedback.

The study of authentic assessment undertaken by Yaseen, O. S. B. (2013, p. 113) confirms that is also depends on the strategies employed. Traditional assessment based on standard testing does not succeed in providing a whole perspective over the students' skills. Evaluations based on performance and observations have become increasingly important.

These aspects are valid in the case of conventional, face-to-face assessments. But what happens when teaching, learning and assessment are pursued online? Gaytan and McEwen (2007, p. 125) analyse the efficiency of the assessment strategies in online education. In a descriptive paper, they investigate the students' perception of the techniques used in online teaching and assessment. The results they have obtained emphasise the need for:

- $\quad$ immediate and permanent feedback;

- the adjustment of the teaching strategies to the students' learning styles;
- designing teaching materials as rigorous as the conventional ones;

- $\quad$ explaining the learning tasks;

- the continuous assessment of students' activity;

- $\quad$ promoting self-assessment, and

- the use of diversified assessment strategies (portfolios, projects).

Indeed, the feedback generated by the direct interaction between teacher and student has a greater formative impact in comparison with other teaching or assessing contexts. Nevertheless, online evaluations allow the optimisation of student's performance, if the teaching strategies, learning tasks or docimologic instruments are connected to some clearly stated objectives.

My opinion is in agreement with the findings of Fook and Sidhu $(2010$, p. 159), who underline that the success of the assessment depends on the selection and use of appropriate evaluation procedures to measure the real performance of the students. Their research targets authentic assessment conducted with the help of a wide range of strategies, such as the portfolio, the study case or the project. Although they ensure the assessment objectivity to a greater extent, the results of the study have emphasised the fact that not all students consider these methods efficient. For example, some students believe that the portfolio is a waste of time, but value the project as a means of authentic assessment, owed to its practical character. All participants in this survey emphasise the importance of promoting formative assessment and of the consistent feedback.

Similarly, in a comparative study, Crundwell (2005) analyses the assessment process from the perspective of making education efficient, as well as the role of assessment at a large scale in the USA and Canada. $\mathrm{He}$ stresses the idea that there is no uniform assessment system in the two states, each area organising its own assessment instruments and procedures, based on their respective objectives. Very important are the applied tests and the communication of the results. A responsible interpretation of these results is required, as they may trigger abuse or injustice. The assessment tools should be valid and reliable, and they must have internal and external consistency. Crundwell emphasises the fact that any assessment should have added value. 
I have selected only a few studies conducted in the field of formative assessment, as the literature in the field is particularly rich. It is a fact that all researchers in this field insist on the formation of the teacher's evaluative skills. The teacher who has these abilities/ competences has clear evaluation options, knows what to assess and what strategies s/he should use, but also how valorise the outcomes in favour of the students. In my opinion, the results of formative assessment should be used as a starting point for future decisions related to the adjustment of the teaching process to the students' learning needs, or else formative assessment would only serve for observation, failing to fulfil its goals.

\section{THE EXPERIENCE OF ROMANIAN EDUCATION}

The latest twenty-five years have witnessed numerous attempts at reforming the Romanian educational system, here including its assessment process. Postmodernism in Romanian education has emphasised the importance of connecting evaluation with teaching and learning, as well as the importance of formative assessment, regardless of the school level.

We must state from the beginning that what we term formative assessment today has always been present in Romanian education, although the formative nature used to be less obvious. Rather, it was about a continuous evaluation accompanying the initial and summative evaluations, its formative implications being relative. What used to be termed continuous evaluation was rather for observation and for administrative purposes, illustrating the rhythm of grading and giving the teacher the chance to grade all the students in a class in a given time interval. Continuous evaluation excessively emphasised the quantification of the results over the qualitative assessment and the decision towards results optimisation. An external assessor had the proof that the teacher was evaluating his/ her students, but the effects of this evaluation were unclear.

Unlike the initial assessment whose aims are to diagnose and to predict the student's future performance, and unlike summative assessment which serves for hierarchies, classifications and certifications, the assessment pursued along the activities carried out in class is the only one able to change the student's learning activity or the teacher's teaching activity. The term "formative assessment" has accentuated in Romania during the repeated attempts made at reforming the Romanian educational system. I believe that some requirements should be met in order to acquire an efficient formative assessment:

- $\quad$ teachers must possess minimal evaluation skills;

- the assessment should be highly objective;

- it should be in agreement with the learning objectives established by the school curriculum;

- $\quad$ the positive assessment (interested in what the student knows or knows how to do) should prevail over the negative one (interested in counting issues);

- a wide range of assessment strategies should be used in order to provide a complete image of the student's performance (without stressing the knowledge dimension exclusively);

- useful and consistent feedback is required;

- $\quad$ students should be involved in the assessment process, which may improve their self-ordered learning skills;

The answers to the questions what and how do we assess are extremely important because, as Perrenoud (2004, p. 9) maintains, a curriculum centred on skills development requires a reassessment of the assessment. Thus, it should not only measure the students' knowledge, but also their competences. In order to evaluate competences, teachers must also possess docimologic skills. Also, Perrenoud insists on the idea of trusting the evaluator, as the students and their parents are entitled at all times to ask for proof of their assessment.

Individualisation and differentiated learning compel the Romanian teacher of today to perform a customised assessment which can motivate the students in their learning activity. In this respect, Cucos (2008, p. 90) considers that the success factor acquires greater importance: "is it something that refers to the individual, in relation to what they have done or what they can do; is it something internal, at the class level, starting from a mean approximated by the teacher, or is it an external criterion, a designed standard imposed by various school policies?"

Assuming that it is correctly carried out and that it meets its aims, formative assessment has a list of strengths that may be noted by both teachers and students: 
- it motivates the students to learn continuously (while the simple, technical evaluation makes the student interested only in getting a good grade, as it is easy to anticipate in most cases);

- $\quad$ it helps the student to become aware of their performance level and to focus on overcoming their difficulties;

- $\quad$ it helps the student to set realistic goals in what their school evolution is concerned, the outcomes representing predictors for future performance;

- it gives the teacher the opportunity to design recovery programmes for improving the results, in agreement with each student's needs and possibilities;

- it produces differentiated and individualized learning;

- it compels the teacher to diversify the assessment strategies so that each student to have the chance to show their potential;

- $\quad$ it ensures the improvement of feedback between teacher and students.

As far as dysfunctionality is concerned, we contend that formative assessment presents no drawbacks in itself. These are rather related to the teacher's mistakes, they are the effects of an assessment which is not carried out from the perspective of its formative character. The practice of current evaluation leaves the teacher with the sensation that everything is carried out in accordance with the principle of equal opportunity. Nevertheless, in many cases, the teacher falls into the trap of formal assessment. It is particularly important to become aware of these aspects, from the perspective of the authentic formative assessment, all the more as evaluation is not a perfect, but a perfectible process.

\section{REFERENCES}

Bennet, R. E. 2011. "Formative assessment: A critical review". Assessment in Education: Principles, Policy \& Practice, 18 1, 5-25. http://dx.doi.org/10.1080/0969594x.2010.513678

Black, P. \& Wiliam, D. 2009. "Developing the theory of formative assessment", EducAsseEvalAcc, 21, 5-31. Retrieved from http://teacherscollegesj.edu/docs/47-developingthetheoryofformativeassessment_12262012101200.pdf

Crundwell, R. M. 2005. "Alternative Strategies for Large Scale Student Assessment in Canada: Is Value-Added Assessment One Possible Answer", Canadian Journal of Educational Administration and Policy, 41. Retrieved from https://www.umanitoba.ca/publications/cjeap/articles/crundwe II.html

Cucoș, C. 2008. Teoria și metodologia evaluării, Editura Polirom, lași

Fook, C. Y. \& Sidhu, G. K. 2010. "Authentic Assessment and Pedagogical Strategies in Higher Education", Journal of Social Sciences, 6 (2), 153-161. http://dx.doi.org/10.3844/jssp.2010.153.161

Gaytan, J. \& McEwen, B. C. 2007. "Effective Online Instructional and Assessment Strategies", American Journal of Distance Education, 21(3), 117-132. http://dx.doi.org/10.1080/08923640701341653

Nyberg, E. \& Olander, M. H. 2015. "A Study of Formative Assessment Strategies in Teachers' School-Based InService Training", International Journal of Learning, Teaching and Educational Research, 11 (1), 53-74

Perrenoud, Ph. 2004. "Évaluer des compétences". L'Éducateur, n spécial "La note en pleine évaluation », 8-11. Retrieved from http://www.unige.ch/fapse/SSE/teachers/perrenoud/php_mai n/php_2004/2004_01.html

Yaseen, O.S.B. 2013. "Educational Assessment Modern Strategies". Journal of Education and Practice, 4 (1)

(c) 2015 Valerica Anghelache; Licensee Lifescience Global.

This is an open access article licensed under the terms of the Creative Commons Attribution Non-Commercial License (http://creativecommons.org/licenses/by-nc/3.0/) which permits unrestricted, non-commercial use, distribution and reproduction in any medium, provided the work is properly cited. 